\title{
Filtration and Breakdown of Clay Clusters during Resin Transfer Molding of Nanoclay/Glass/Epoxy Composites
}

\author{
Levent Aktas, Sudha Dharmavaram, Youssef K. Hamidi \\ AND M. CENGIZ AltAN* \\ School of Aerospace and Mechanical Engineering \\ The University of Oklahoma, Norman, OK 73019, USA
}

\begin{abstract}
Dispersion of nanoclay clusters during resin transfer molding of nanoclay/glass/epoxy disks is investigated. In addition to a center-gated disk containing only $14 \%$ glass fibers, three nanocomposite disks are fabricated with the addition of 2, 5 or $10 \mathrm{wt} \%$ Cloisite $^{\circledR} 25 \mathrm{~A}$ nanoclay. The spatial distribution of nanoclay clusters along the radial axis of the nanocomposite disks are characterized at two length scales. Clusters larger than $1.5 \mu \mathrm{m}$ are characterized by performing image analysis on the SEM micrographs whereas smaller nanoclay clusters are identified by wavelength dispersive spectrometry. Results obtained from image analysis indicate that nanoclay clusters are filtered out by as much as $50 \%$ in the flow direction by the glass fiber preforms. In addition, increasing nanoclay content led to higher filtration, suggesting that cluster formation is more prominent at higher nanoclay loadings. Cluster size distribution analyses revealed that the outer edges of the disks, on average, contain finer nanoclay particles. For instance, the outer edge of the nanocomposite with $2 \%$ clay contains $22 \%$ more small nanoclay clusters compared to center of the disk. Glass transition temperature, $T_{g}$, of four specimens obtained from each molded disks is characterized under oscillatory shear. Glass transition temperature of the samples are shown to increase with the nanoclay content, yielding a $40 \%$ higher $T_{g}$ at $10 \%$ nanoclay loading compared to glass/epoxy composite without clay. Increasing glass transition temperature with increasing nanoclay content may be an indication of intercalation of nanoclay within the epoxy matrix.
\end{abstract}

KEY WORDS: resin transfer molding, nanoclay filtration, electron microprobe analysis.

\section{INTRODUCTION}

T HERMO-PHYSICAL PROPERTIES OF polymers can be significantly altered by the addition of micron- or nano-scale particulates. Conventional fillers such as silica are known to enhance stiffness while resulting in strength reductions [1]. The introduction of nanometer-scale particulates such as carbon nanotubes and nanoclay has proven to

*Author to whom correspondence should be addressed. E-mail: altan@ou.edu 
improve strength, stiffness, and thermal properties of polymers, simultaneously [2]. Among the nano-scale particulates, nanoclay has gained acceptance as an additive to polymers owing to its low cost and accessibility [3]. Although its layered structure and various properties have been known since the early 1930s [4], utilization of nanoclay to enhance polymers was introduced by the pioneering work conducted at Toyota Research Labs [5-8]. The inability to disperse nanoclay into polymeric materials was overcome by exchanging the sodium ion in the hydrophilic nanoclay with ammonium cations of $\omega$-amino acids [5].

Following the results obtained by Toyota Research Labs, several researchers attempted to utilize nanoclay in various thermoplastic polymers [9-16]. Among these studies, Cho and Paul [9] comparatively analyzed the mechanical property improvements as a result of adding montmorillonite, organoclay (i.e., cation exchanged montmorillonite) or glass fiber in nylon 6 matrix. The addition of $5 \mathrm{wt} \%$ organoclay led to 30 and $37.6 \%$ improvements in tensile strength and stiffness over the pristine nylon 6 matrix. When the effectiveness of cation exchange was considered, it was reported that utilization of organoclay provides 10.6 and $21.6 \%$ higher strength and stiffness, respectively over the nanocomposite fabricated with identical amount of montmorillonite. On the other hand, the strength improvement provided by organoclay reinforced nylon 6 was observed to be $14.9 \%$ higher than that of $30 \%$ glass fiber reinforced nylon 6. Maiti et al. [10] investigated the effect of nanoclay on the high temperature dynamic mechanical properties of polypropylene. Maleic anhydride grafted polypropylene (PP-MA) was blended with cation exchanged nanoclay at loadings ranging from 2 to $7.5 \mathrm{wt} \%$ and melt extruded. Over the range of nanoclay loading, the storage modulus of polypropylene is observed to increase by 156 and $164 \%$ for the loading temperatures of 70 and $130^{\circ} \mathrm{C}$, respectively.

Publications on mixing nanoclay with thermosetting resins became available during the last decade [17-23]. Among these, a noteworthy study is performed by Lan and Pinnavaia [17]. Authors prepared organoclays by ion-exchange reaction with alkylammonium chloride or bromide salts with carbon numbers ranging from 8 to 18 . The organoclay was then mixed with epoxy resin at several loadings up to $23.2 \mathrm{wt} \%$ and allowed to cure by the addition of Jeffamine D2000 curing agent. Reaffirming the study conducted by Toyota Research Labs. [6], Lan and Pinnavia observed increasing strength and stiffness with increasing carbon number. Strength and stiffness were both observed to increase with nanoclay content and were observed to be 18-fold and 12-fold higher compared to pristine epoxy, respectively. However, the choice of Jeffamine D2000 resulted in a sub-ambient glass transition temperature for the epoxy matrix. As the authors [17] stated, the improvements observed in a glassy matrix was rather limited. Similarly, Abot et al. [18] investigated the effects of two commercially available nanoclay types, Cloisite ${ }^{\circledR} 30 \mathrm{~B}$ and Nanomer ${ }^{\circledR}$ I.28E. These two nanoclay types were mixed with epoxy resin at loadings up to $20 \mathrm{wt} \%$. The mechanical tests indicate that the tensile modulus improved by $31 \%$ whereas the tensile strength deteriorated up to $28 \%$.

In addition to affecting mechanical properties, nanoclay is proven to improve the heat distortion temperature [2,3], flame retardant behavior [3,24] and resistance to gas permeation [25]. In particular, nanoclay is shown to form a thermal barrier layer [24] and protect the polymer from degradation under extreme thermal conditions. Based on the existing literature, improvement in mechanical properties due to the addition of nanoclay in thermosetting resins can be viewed as modest. In fact, similar improvements can also be achieved by utilizing conventional fiber reinforcements. Thus, nanoclay, at present, might gain acceptance as an additive in conventional fiber reinforced composites. By doing so, 
one would aim at improving mechanical properties as well as the thermal and barrier properties of the conventional polymer composites. For example, Haque et al. [26] added Nanomer ${ }^{\circledR}$ I28.E nanoclay into glass/epoxy composites. The authors blended 1, 2, 5, and $10 \mathrm{wt} \%$ of nanoclay into epoxy resin, mixed with curing agent and fabricated nanocomposite samples reinforced with woven glass fiber preforms by vacuum assisted resin infusion method (VARIM). Thermogravimetric analysis indicated that by the addition of $1 \mathrm{wt} \%$ nanoclay, the onset of decomposition temperature increased by $10.6 \%$.

As Haque et al. [26] and many others [27,28] stated, agglomeration of nanoclay in the polymeric matrix may be the primary reason for not achieving higher levels of property enhancement. Most of the time, the desired level of dispersion quality cannot be achieved and nanoclay appears in a phase separated form within the polymer matrix. As indicated by Cai and Salovey [29] and others [30,31], in the case of micro-composites, cluster sizes and their distribution are significant factors in determining the final properties of the part. To the best of our knowledge, size and spatial distribution of nanoclay clusters in resin transfer molded composites has not been reported.

Traditionally, dispersion of nanoclay in polymer matrices is characterized by two methods, transmission electron microscopy (TEM) and X-ray diffractometry (XRD). Transmission electron microscopy is utilized to image individual nanoclay platelets. By characterizing the position of nanoclay platelets relative to each other, a qualitative judgment for the dispersion state is usually made. Intricate and tedious sample preparation, however, most often limits the application of transmission electron microscopy to few samples. Hence, few and small imaging areas probed by TEM may not be representative of the entire sample [32]. This drawback becomes especially important if considerable spatial variation in dispersion quality is expected. X-ray diffractometry, on the other hand, serves as a quantitative tool to characterize dispersion by measuring the average spacing between nanoclay platelets at atomic resolutions. XRD involves transmitting a well defined X-ray onto the sample and collecting the reflected rays. When the Bragg condition [33] is satisfied, the energy of the reflected X-ray registers a peak, which is used in determining the average platelet spacing at which the diffraction takes place. However, the samples with a broad distribution of gallery spacing may result in indistinguishable peaks and hence result in inaccurate conclusions about the state of dispersion [28].

In the current study, we present dispersion characterization of nanoclay in resin transfer molded glass/epoxy disks. In addition to a glass/epoxy disk without nanoclay, three disks containing 2, 5, and $10 \mathrm{wt} \%$ nanoclay are fabricated. Dispersion of nanoclay clusters is characterized at two length scales. Nanoclay clusters larger than $1.5 \mu \mathrm{m}$ are characterized by performing digital image analysis on the scanning electron micrographs whereas smaller nanoclay clusters are accounted for by wavelength dispersive spectrometry. In addition to radial cluster size and shape distribution, effect of nanoclay on the glass transition temperature of glass/epoxy composites is investigated.

\section{EXPERIMENTAL STUDIES}

\section{Materials}

Cloisite $^{\circledR} 25 \mathrm{~A}$ of Southern Clay Products (Gonzales, TX) is selected as the nanoclay used in this study. Cloisite ${ }^{\circledR} 25 \mathrm{~A}$ is a natural montmorillonite modified with quarternary 
ammonium salt to increase its compatibility with various resins and increase the $d$-spacing to let polymer chains intercalate. The $d$-spacing reported by the supplier is $18.6 \AA$ which is $59 \%$ higher than the natural montmorillonite of Southern Clay Products [34]. The fiber reinforcement is provided by placing several layers of randomly oriented chopped strand glass fiber preforms (Fiberglast, Part No. 248) into the mold cavity. This specific type of preform has a planar density of $0.2280 \mathrm{~kg} / \mathrm{m}^{2}$. Resin transfer molding is performed with Epon 815C epoxy resin (Shell Chemicals). EPON 815C resin is primarily DGEBA type of epoxy blended with HELOXY ${ }^{\circledR}$ modifier to increase its wetting characteristics and reduce viscosity. The density of Epon $815 \mathrm{C}$ is given as $1.13 \mathrm{~g} / \mathrm{cm}^{3}$ by the supplier. Epon $815 \mathrm{C}$ is cured with Epi-cure 3282 curing agent with a mixing ratio of $5: 1$ by weight as suggested by the supplier.

\section{Mixing Nanoclay in Epoxy Resin}

Mixing of nanoclay in epoxy resin is facilitated by a sonicator prior to resin transfer molding. As the resin is sonicated in a glass beaker, desired amount of nanoclay is slowly added into the batch. Initially, nanoclay/epoxy blend is hand mixed for $5 \mathrm{~min}$ in order to initiate and accelerate cluster breakdown. The sonication is then allowed to continue for $1 \mathrm{~h}$ in order to achieve an effective dispersion and a homogenous suspension. At the end of dispersion period, small air pockets are observed on the surface of the nanoclay/epoxy blend. These air pockets are removed from the surface prior to molding. The viscosities of the resin/nanoclay mixtures are measured using Brookfield DV-II+ viscometer and found to be $0.8,1.12$, and $3.69 \mathrm{Pas}$ for 2,5 , and $10 \mathrm{wt} \%$ nanoclay, respectively. Considering the viscosity of the neat Epon $815 \mathrm{C}(0.65 \mathrm{~Pa} \mathrm{~s})$, nanoclay is observed to result in substantial increases in viscosity. The mixture is then transferred into the resin reservoir of the molding set-up for resin transfer molding (RTM) process.

\section{Resin Transfer Molding and Sample Preparation}

Resin transfer molding is performed using a custom made molding set-up. The set-up is composed of a hydraulic press, two cylinders serving as reservoirs for resin and curing agent, and a set of plungers for injecting out the contents of the reservoirs. The inner diameters of both cylinders are machined to yield the stoichiometric ratio of $5: 1$ resin to curing agent. The resin and curing agent leaving the resin reservoirs are merged with a $t$-connector. Before entering the mold, the resin and curing agent mixture pass through an in-line static mixer with 32 helical mixing units to ensure thorough mixing. This experimental molding set-up is depicted in Figure 1 and elsewhere [35,36]. After passing through the static mixer, the nanoclay/resin/curing agent mixture is injected into a mold that is placed in-line with the molding set-up. The mold is composed of a $3.2 \mathrm{~mm}$ thick spacer plate placed between $6.35 \mathrm{~mm}$ thick aluminum mold walls. The $152.4 \mathrm{~mm}$ diameter circle cut out of the spacer plate forms a disk-shaped mold cavity.

A total of four disks are fabricated with the aforementioned process at a flow rate of $5.3 \mathrm{~cm}^{3} / \mathrm{s}$. Each of the four disks contains six layers of fiber preform, resulting in a fiber volume fraction of approximately $14 \%$. One of the disks does not contain nanoclay, whereas remaining three disks comprise 2, 5, and $10 \mathrm{wt} \%$ nanoclay in their matrices, respectively. Olivero et al. [35] studied the permeability of identical fiber mats in similar 
molding configurations as a function of fiber volume fraction. Based on their data, permeability of the current fiber reinforcement is estimated to be $5.4 \times 10^{-9} \mathrm{~m}^{2}$. Following the molding process, the molds are kept at room temperature for two days to complete curing. At the end of two days, the disks are demolded and post-cured in an oven at $40^{\circ} \mathrm{C}$ for $24 \mathrm{~h}$.

The dispersion of nanoclay is investigated along the radius of the disks with 2,5 , and $10 \mathrm{wt} \%$ nanoclay. Therefore, a $63.5 \mathrm{~mm}(2.5 \mathrm{in})$ radial section of these three disks are cut and their through-the-thickness surfaces are analyzed. In addition to the radial sample for dispersion characterization, four other samples from each of the four disks are cut out for dynamic mechanical analyses (DMA). The spatial distribution of samples is schematically depicted in Figure 2.

\section{Characterization of Nanoclay Dispersion}

In nanoclay added polymeric composites, considerable amount of nanoclay clusters at micron scale $(1-10 \mu \mathrm{m})$ are likely to exist in addition to the intercalated and exfoliated sub-micron scale platelets. In order to understand and predict the thermo-physical properties of the resulting nanocomposite, the detailed analysis of the nanoclay clusters as well as intercalated and exfoliated nanoclay is necessary. Thus, one needs to consider all relevant length scales, especially when phase-separation might be the dominating dispersion state. Traditional methods, such as TEM and XRD are effective in determination of intercalation and exfoliation, however both are unable to characterize

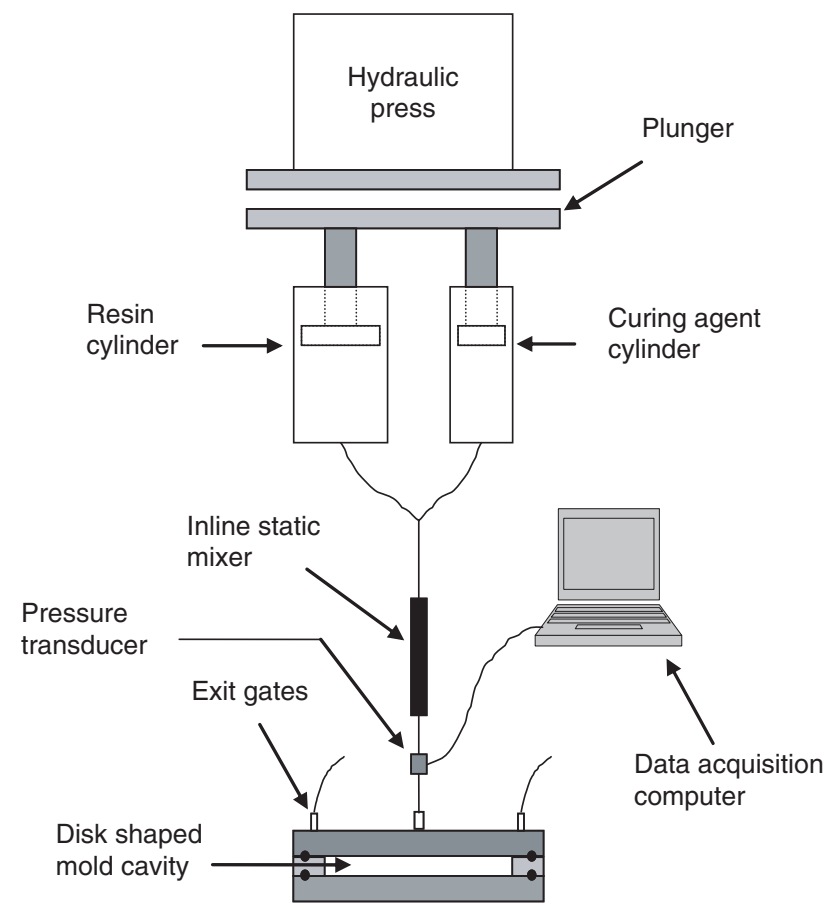

Figure 1. Experimental molding set-up used to fabricate resin transfer molded composite disks [35,36]. 


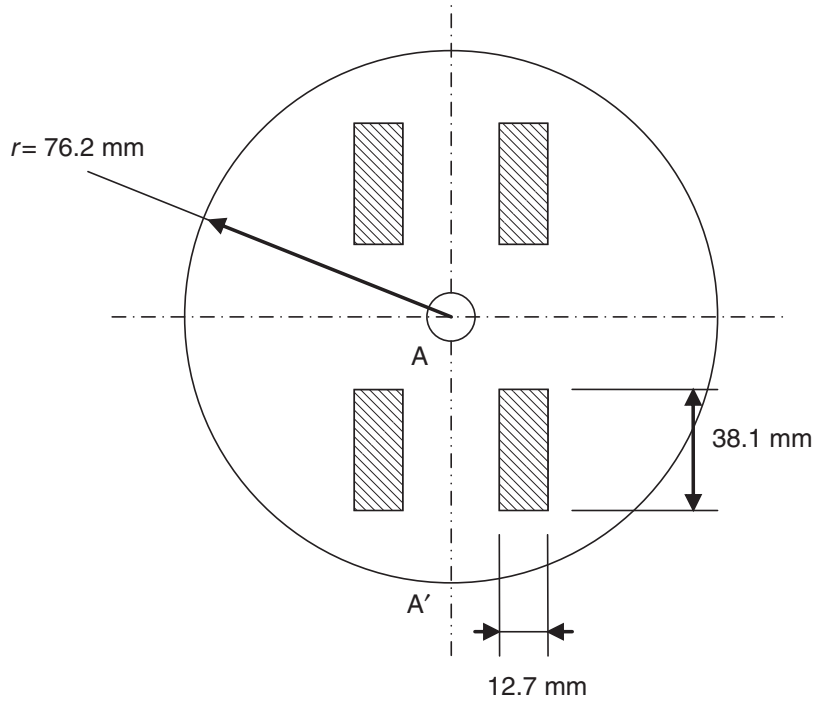

Figure 2. Spatial distribution of test samples on a molded disk. The shaded samples are used to determine the glass transition temperature. Dispersion characterization is performed through-the-thickness at section $A-A^{\prime}$.

larger clusters due to their small working area and limited spatial coverage. In order to characterize a larger surface area and enhance the spatial coverage, an electron microprobe analyzer (EMPA) is utilized. A Cameca SX50 electron microprobe analyzer (EMPA) is implemented to characterize the dispersion of nanoclay clusters at various locations of the molded nanocomposite. In addition to its scanning electron microscopy imaging capability, this particular EMPA enables compositional analysis via five wavelength dispersive spectrometers (WDS) and an energy dispersive spectrometer (EDS). The five wavelength dispersive spectrometers are positioned symmetrically around the column and enable precise compositional analysis of the sample for elements with atomic numbers 5 (i.e., boron) and above. Having multiple wavelength dispersive spectrometers enables simultaneous analysis of several elements with properly chosen diffraction crystals. Energy dispersive spectrometer, on the other hand, serves as a rapid preliminary compositional analysis tool to determine the elements that are to be targeted by WDS. In addition to its advanced compositional analysis capability, being able to accept large samples makes EMPA a suitable tool for identifying nanoclay presence at length scales smaller than $1 \mu \mathrm{m}$ in larger RTM samples.

Due to the planar isotropy of the glass reinforcement, the flow and the distribution of nanoclay clusters is expected to be axis-symmetric in a molded, center-gated disk. Thus, characterization of the distribution of nanoclay clusters is carried out on one radial sample cut out from each disk containing 2, 5, and $10 \mathrm{wt} \%$ nanoclay. Although throughthe-thickness variation of nanoclay morphology might be observed as a result of varying shear rates, the emphasis in this study is on the radial variation of nanoclay content and size. Most likely, such variations in the radial direction will induce significant property variations, and thus produce a nonhomogeneous product. In order to perform EMPA analysis to quantify nanoclay dispersion, these samples are slightly polished with 100 grit sand paper and embedded into EMPA sample holders such that their throughthe-thickness surface is exposed to the electron beam for analysis. Since wavelength 


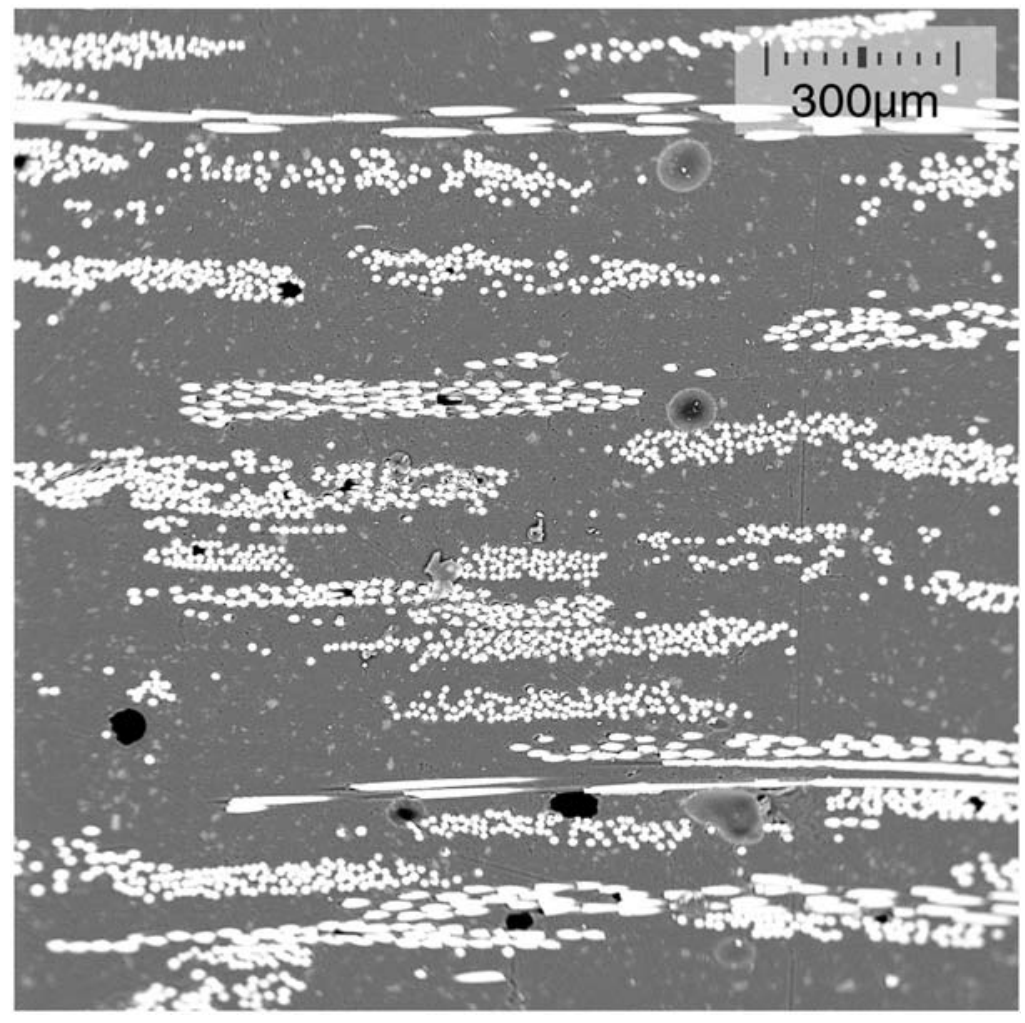

Figure 3. As captured SEM micrograph used for characterization of micro-scale nanoclay cluster distribution. Fibers, nanoclay clusters and voids can be identified in the epoxy matrix.

dispersive spectrometry is sensitive to surface irregularities [37], the samples are polished using aluminum oxide lapping films with particle sizes ranging from 12 to $1 \mu \mathrm{m}$. Further polishing is performed using diamond suspensions with particle sizes as small as $50 \mathrm{~nm}$.

Initial observations of the surface microstructure using the scanning electron microscope mode reveal the existence of nanoclay in the form of clusters. Subsequent examinations at various magnifications ranging from $50 \times$ to $2500 \times$ indicate a continuum of clusters ranging from over $10 \mu \mathrm{m}$ to submicron levels. Thus, the characterization of nanoclay clusters is performed by two different methods to identify nanoclay at two length scales, i.e., micro-scale and nano-scale clusters. The micro-scale analysis involves characterization of nanoclay clusters that are visible in SEM micrographs at $50 \times$ magnification. At that magnification, smallest identifiable nanoclay cluster is $1.5 \mu \mathrm{m}$. It should be noted that $1.5 \mu \mathrm{m}$ corresponds to the length of one pixel at the image resolution of $1024 \times 1024$ pixels. All micro-scale nanoclay clusters identifiable by digital image analysis on these 50× SEM micrographs are captured. Remaining nano-scale clusters which are invisible on SEM micrographs are probed by WDS.

For the characterization of micro-scale clusters, back scattered scanning electron micrographs are captured along the radial center-line of each of the three samples (i.e., comprising 2, 5, and $10 \mathrm{wt} \%$ nanoclay) at $20 \mathrm{kV}$ accelerating voltage. The images are taken at $4 \mathrm{~mm}$ intervals of approximately $63.5 \mathrm{~mm}$ long samples. A demonstrative as captured SEM micrograph is depicted in Figure 3. In Figure 3, a total of four phases 


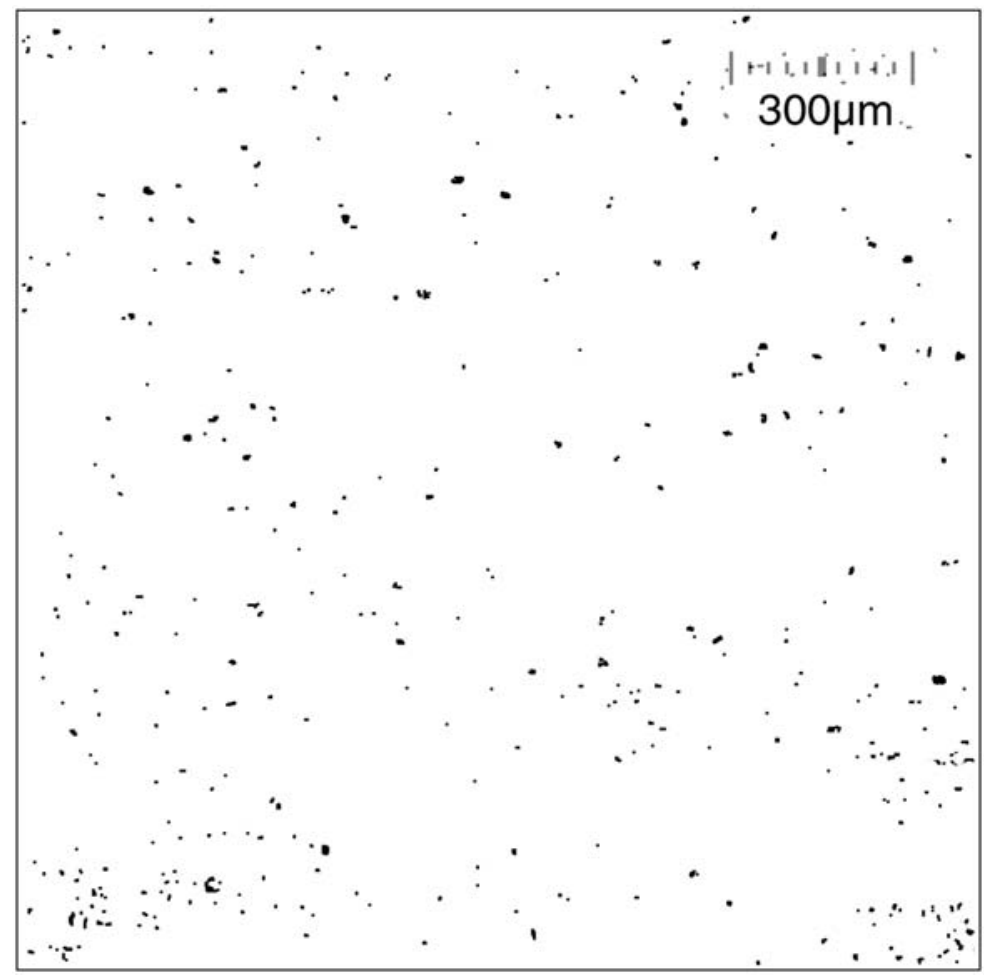

Figure 4. The SEM micrograph after thresholding process for modal analysis.

can be identified: the epoxy background, glass fibers, nanoclay clusters, and voids. Glass fibers can be recognized as white, circular geometries. The fibers that are perpendicular to the plane of the image are perfect circles, while the ones that are at an angle form elliptical geometries. Nanoclay clusters have a grey color and appear to be uniformly scattered in the epoxy matrix whereas voids appear as black circles or concentric circular shades of gray depending on their depth from the sample surface. The detailed analysis of size and morphology of the voids observed in these samples are reported by Hamidi et al. [38]. Before any analysis of nanoclay clusters, these voids were blanked using Adobe Photoshop ${ }^{\circledR}$ software. The images are then analyzed using Image Tool $^{\circledR}$ software. Each image along the sample radius is thresholded for the gray scale of the nanoclay clusters to determine the nanoclay content of the epoxy matrix. The thresholded version of Figure 3 is shown in Figure 4. The resulting binary images are then subjected to modal analysis to account for their nanoclay content, size, and number density.

The nano-scale clusters are identified using wavelength dispersive spectrometry. Prior to WDS analysis, the composition of a Cloisite ${ }^{\circledR} 25 \mathrm{~A}$ was analyzed by EDS to determine the elements to be targeted by WDS. The beam damage is known to affect the WDS results. Thus, to assess the amount of damage imparted on the analytical volume, the pristine polymer is subjected to several beam conditions for different times. As a result, a beam current of $5 \mathrm{nA}$ at an accelerating voltage of $20 \mathrm{kV}$ is chosen to be applied to a spot of $20 \mu \mathrm{m}$ in diameter. These settings yield accurate results while maintaining sample integrity. 
A total of 353 points obtained at $500 \mu \mathrm{m}$ intervals from three samples are analyzed by WDS.

\section{Dynamic Mechanical Analysis}

Dynamic mechanical analysis with the purpose of determining the glass transition temperature is carried out using RDA-III rheometer (Rheometric Scientific). Approximately $38 \times 13 \times 3.2 \mathrm{~mm}$ rectangular samples are subjected to oscillatory torsion with a frequency of $1 \mathrm{~Hz}$ as the temperature is ramped from room temperature to $121^{\circ} \mathrm{C}$ at a rate of $1{ }^{\circ} \mathrm{C} / \mathrm{min}$. Glass transition temperature of four samples from each of the four disks (i.e., $0,2,5$, and $10 \mathrm{wt} \%$ nanoclay content) are measured.

\section{RESULTS}

\section{Dispersion of Micro-scale Clusters}

Although it is desirable to have the nanoclay fully exfoliated into individual platelets, the frequently observed outcome of nanoclay inclusion in epoxy resins may be the formation of micro-scale clusters with dimensions in the order of $1-50 \mu \mathrm{m}$. The size, morphology, and spatial distribution of such clusters within the polymer matrix will considerably affect the thermo-mechanical properties of the resulting nanocomposite. The size variations and spatial distribution of these clusters throughout a composite part will also yield important clues about the effect of processing conditions on cluster breakdown and exfoliation.

Haque et al. [26] and others [21,22,38] investigated using nanoclay as an additive to conventional fiber reinforcement to improve specific properties. The interaction of nanoclay with fiber reinforcement, however, has not been thoroughly investigated. Especially, in the case of liquid composite molding processes, the flow of nanoclay clusters may be blocked by the fiber bed and result in non-homogenous part due to clay segregation. In addition, nanoclay clusters may even break down due to the flow kinematics of the mold filling process [39].

Figure 5 depicts the volume fraction of micro-scale clusters along the radius of disks containing 2, 5, and $10 \mathrm{wt} \%$ nanoclay. The error bars in Figure 5 are formed by performing the image analysis five times to reduce the uncertainty associated with the thresholding process and to determine the $95 \%$ confidence interval. For clarity, we need to emphasize that Figure 5 shows the area fraction of the identified nanoclay clusters. Thus the area fraction determined by applying the thresholding process on digital scanning electron microscopy images is termed nanoclay cluster content. The internal structure of a nanoclay cluster is often complex, involving intercalated matrix material and trapped air pockets. When identified by scanning electron microscopy at $50 \times$, these complex structures are viewed as parts of the nanoclay clusters. Therefore, the nanoclay cluster content - when determined by scanning electron microscopy - may overestimate the actual nanoclay content.

Glass/epoxy disk containing only $2 \mathrm{wt} \%$ nanoclay do not show significant radial variation of the micro-scale nanoclay clusters. The average nanoclay volume 

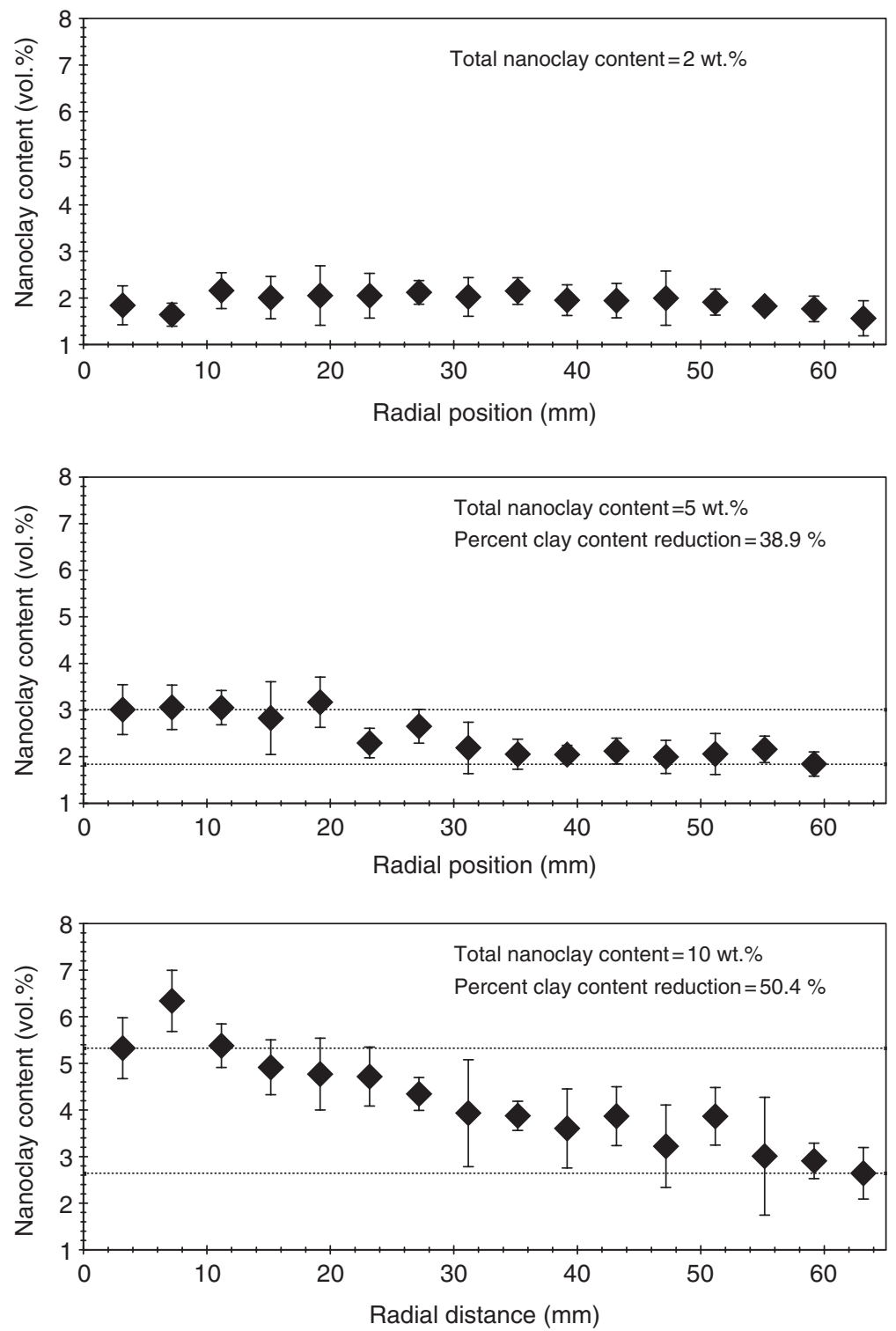

Figure 5. Micro-scale nanoclay content distribution along the radius for nanocomposites fabricated with 2, 5 and 10 wt\% Cloisite ${ }^{\circledR} 25 \mathrm{~A}$ nanoclay.

fraction is $1.94 \%$. However, for disks having 5 and $10 \mathrm{wt} \%$ nanoclay, the micro-scale clusters decrease significantly along the radius, indicating filtration of nanoclay by the glass fiber preform. As shown in Figure 5, the micro-scale cluster content in these disks decrease by 38.9 and $50.4 \%$ between the inlet and the outer edge of the disk. Such a steep reduction in the cluster content is expected to result in significant spatial variations in the thermo-mechanical properties of the nanocomposite. As the glass fiber preforms in all three disks were the same, similar filtration behavior would be expected in all three disks. 

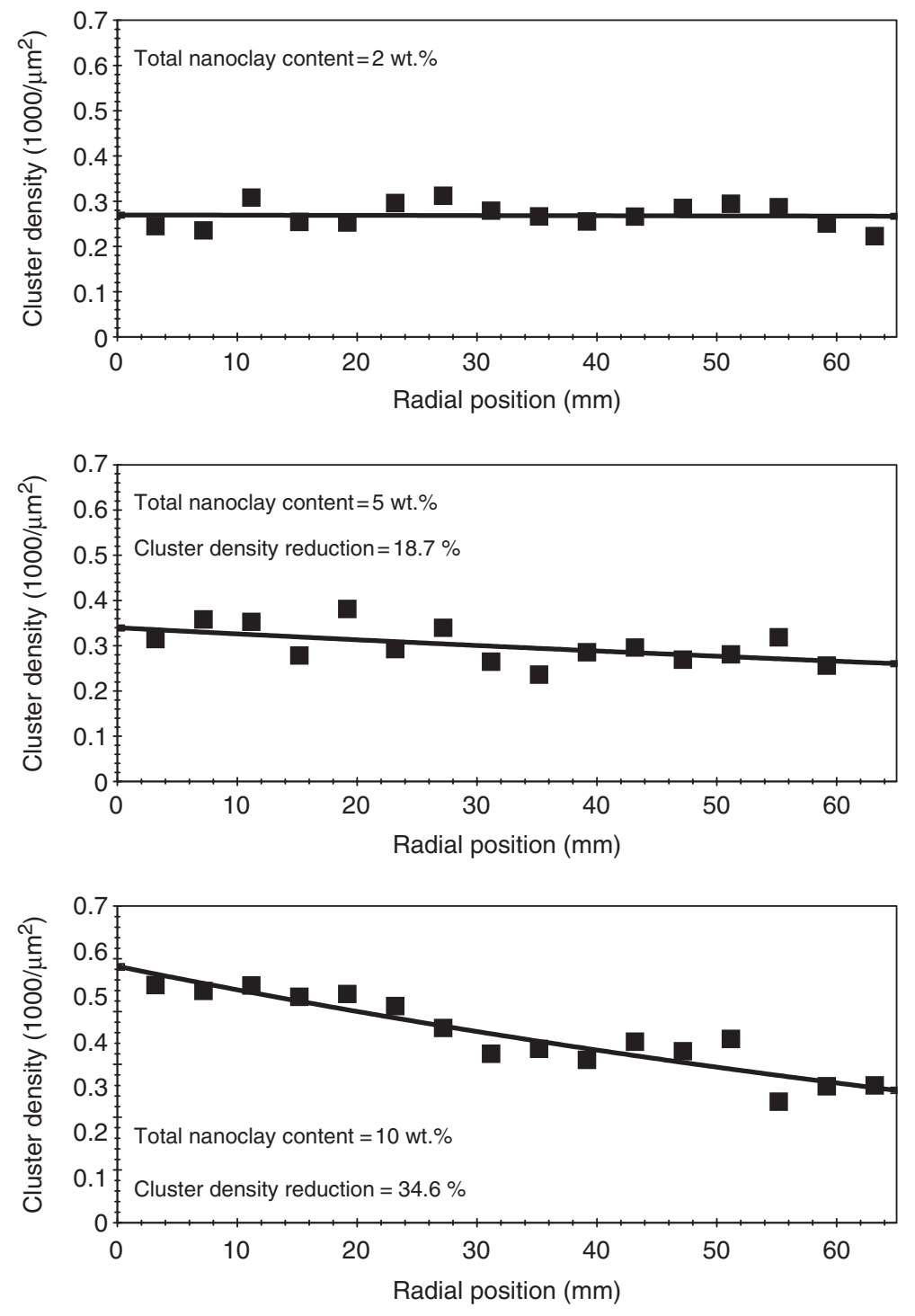

Figure 6. Change in nanoclay cluster density along the radius.

However, the increase in nanoclay filtration at higher clay loadings indicates increased agglomeration of clay and formation of larger clusters. Hence, the effectiveness of sonication in dispersing nanoclay seems to be reduced as the clay content is increased.

The filtration of nanoclay by the glass fiber preform will lead to non-uniform cluster sizes along the disks' radius. In addition, some of the larger clusters might be broken into smaller sizes. Thus, radial variation of nanoclay cluster content and cluster density (i.e., number of nanoclay clusters per unit area) yield information about the size variation of clusters. Figure 6 depicts the cluster density variation in the radial direction for each disk. Each data point in Figure 6 is calculated by dividing the number of clusters in the corresponding image with the actual imaging area. It is observed that the cluster density 

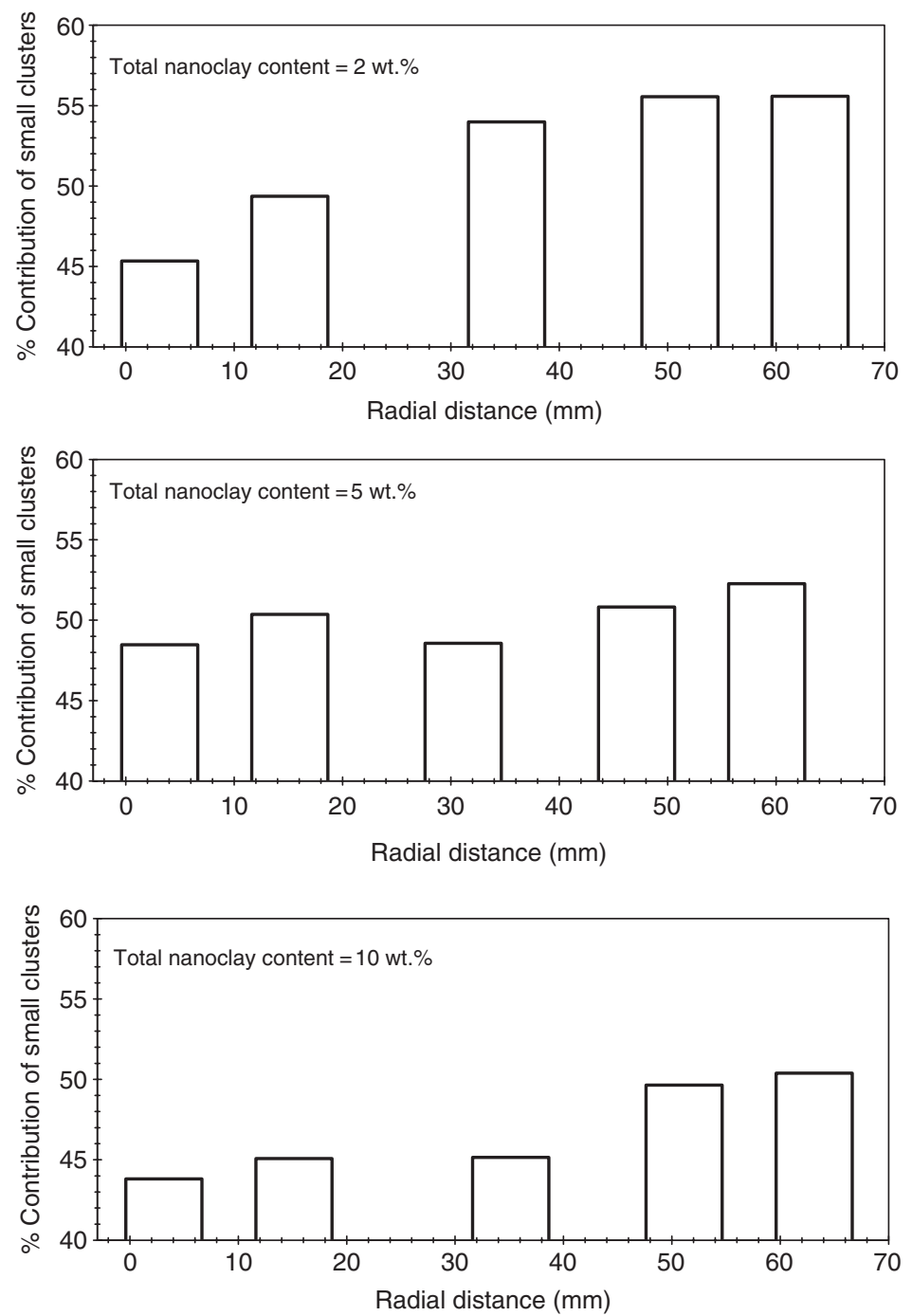

Figure 7. Contribution of small $\left(A<40 \mu \mathrm{m}^{2}\right)$ nanoclay cluster to the overall nanoclay content along the radius.

for the composite with $2 \mathrm{wt} \%$ nanoclay remained constant. However, akin to the cluster content, cluster density in the radial direction experienced significant reductions for nanocomposites with 5 and $10 \mathrm{wt} \%$ nanoclay. For $5 \mathrm{wt} \%$ nanoclay loading, the cluster density decreased by $18.7 \%$ from the inlet to the outer edge of the disk, whereas the decrease is observed to be $34.6 \%$ for the $10 \mathrm{wt} \%$ nanoclay.

Although both the nanoclay cluster content and density are decreasing radially for 5 and $10 \mathrm{wt} \%$ loadings, the decrease in cluster content is more than that of cluster density. If the average size of nanoclay clusters were radially uniform in a particular disk, the percentage decrease in nanoclay cluster content and density would be the same. Thus, results shown in Figures 5 and 6 indicate that clusters close to the inlet are larger than those at the outer edges of the disk. In order to verify this, the radial distribution of small nanoclay clusters (i.e., area $<40 \mu \mathrm{m}^{2}$ ) in each disk is shown in Figure 7. Regardless of the nanoclay content, 

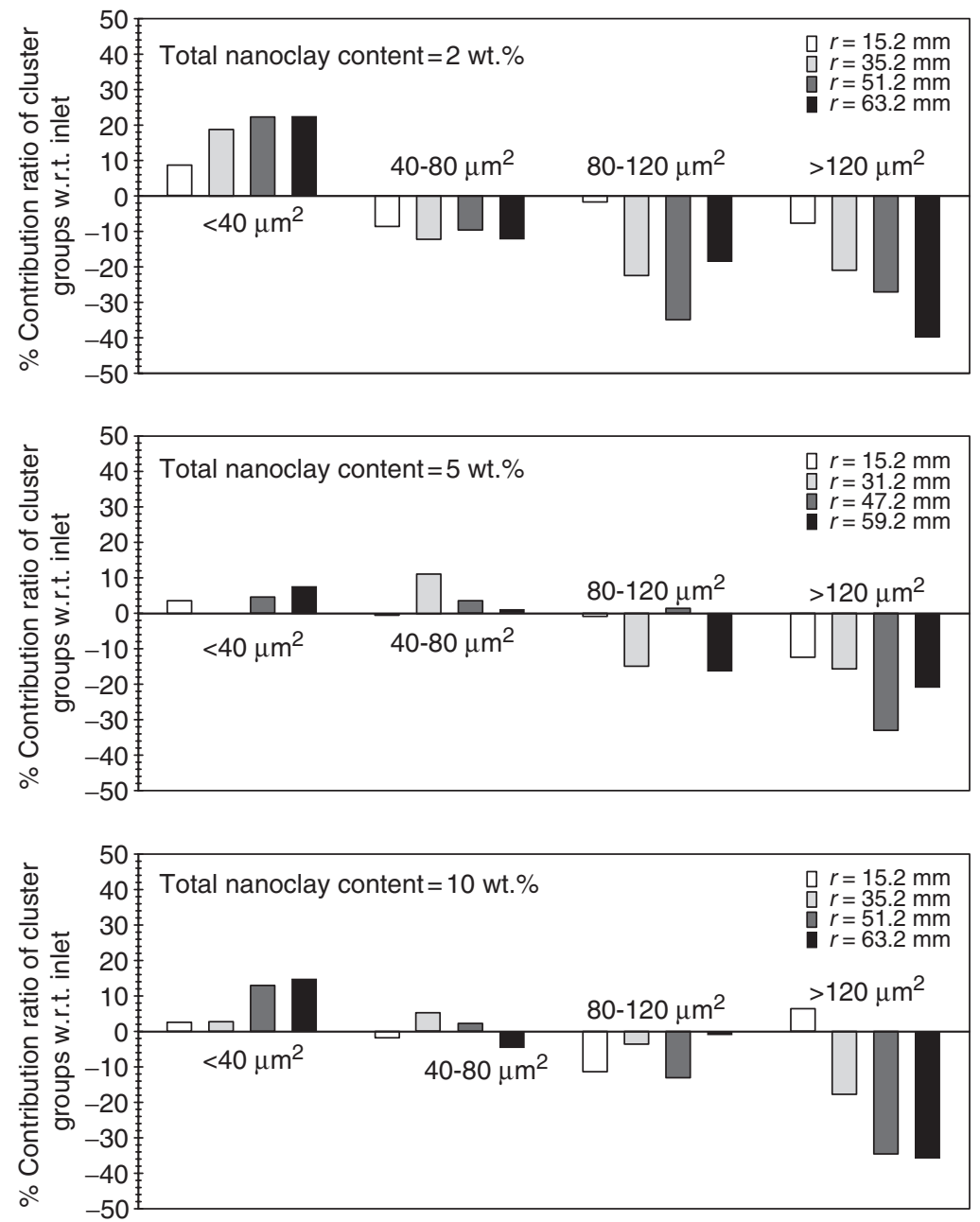

Figure 8. Percent contribution ratio of nanoclay clusters calculated with respect to the inlet at various radial locations.

small nanoclay clusters make up a greater portion of the nanoclay content at the outer edges of the disk. In Figure 7, the percent contribution of small clusters is shown to increase from 45.3 to $55.6 \%$ for $2 \mathrm{wt} \% ; 48.5 \%$ to $52.3 \%$ for $5 \mathrm{wt} \%$; and 43.8 to $50.4 \%$ for $10 \mathrm{wt} \%$ nanoclay loadings.

Results obtained from Figures 5-7 verify a preferential cluster size distribution in the radial direction of the nanocomposite disks. A more thorough assessment of radial nanoclay size distribution can be made by analyzing a wider range of nanoclay cluster sizes. To achieve this, micro-scale nanoclay clusters are divided into four categories depending on their areas, $A$. These categories are nanoclay clusters with (i) $1.5 \mu \mathrm{m}<A<40 \mu \mathrm{m}^{2}$, (ii) $40 \mu \mathrm{m}^{2} \leq A<80 \mu \mathrm{m}^{2}$, (iii) $80 \mu \mathrm{m}^{2} \leq A<120 \mu \mathrm{m}^{2}$, and (iv) $A \geq 120 \mu \mathrm{m}^{2}$. Percentage contribution of different nanoclay sizes are determined with respect to the inlet content (i.e., at $r=0$ ) and depicted in Figure 8. This is realized by 
dividing the percentage contribution of each cluster category to the percentage contribution of the same category at the inlet. For example, for the case of $2 \mathrm{wt} \%$ nanoclay content, clusters with $A>120 \mu \mathrm{m}^{2}$ make up $12.6 \%$ of the total clusters at the inlet, whereas same size cluster group make up 11.6, 9.9, 9.2, and 7.5\% of the total clusters at $r=15.2,35.2,51.2$, and $63.2 \mathrm{~mm}$, respectively. Thus, Figure 8 shows the percentage contribution ratio of clusters with $A>120 \mu \mathrm{m}^{2}$ as $-8.0,-21.2,-27.4$, and $-40.1 \%$. Percentage contribution analyses of different cluster sizes for all three disks clearly indicate that, regardless of nanoclay content, the clusters are becoming finer along the disks' radii.

The radial distribution of various nanoclay cluster sizes presented in Figures 5-7 may form as a result of two distinct mechanisms: filtration of nanoclay clusters by the fiber preform and breakdown of nanoclay clusters due to flow kinematics. In a previous study [39], a similar cluster distribution analysis was made for a disk without fiber reinforcement. It was observed that the nanoclay cluster content was constant in the radial direction, however cluster density was increasing. This behavior was attributed to cluster breakdown resulting in finer nanoclay clusters towards the outer edges of the disk. However if the only mechanism causing this distribution is nanoclay cluster breakdown, than one would expect nanoclay cluster density to increase in the radial direction, due to formation of new small clusters broken from the larger ones. Therefore, nanoclay filtration is shown to be a major factor in the formation of the current nanoclay distribution illustrated in Figures 5-8.

On the other hand, gaps between fiber preform layers (e.g., see Figure 3) could be large enough for some of the clusters to move with the flow without being affected by the fibers. In general, flow of resin between the fiber preform layers may have two possible effects on the nanoclay clusters: (i) smaller clusters may move farther than the larger ones due to inertia effects and accumulate at the outer edges of the disk, and (ii) the clusters may breakdown into smaller pieces due to the viscous stresses governed by local micro-scale flow kinematics. Viscous nature of the resin and the relatively low volume flow rate indicate a Reynolds number at the order of $10^{-4}$ and $10^{-5}$. Such small Reynolds numbers indicate Stokes flow with negligible inertial effects. Hence, all clusters are expected to move with the flow without sustaining a relative velocity during mold filling. However, due to the small gap thickness of the mold geometry, these particles will be subjected to viscous shear forces. In addition, the radial geometry would result in a decelerating flow, which in turn results in radial compressive stresses. The combination of viscous shear and extensional forces are likely to break down nanoclay clusters as they move radially outward with the resin.

It is believed that, in addition to filtration by the fiber preforms, the breakdown of nanoclay clusters due to the flow kinematics is likely to have developed the nanoclay cluster distribution observed in this study.

\section{Dispersion of Nano-scale Clusters}

As indicated in the previous sections, spatial coverage of the nanoclay dispersion analysis should be sufficiently large to represent the entire sample. To accomplish this, micro-scale clusters are identified by scanning electron microscopy at various locations. The clusters that are not identifiable by the SEM micrographs should also be quantified. The clay which is not visible in SEM images has planar dimensions under $1.5 \mu \mathrm{m}$ as mentioned earlier. Based on the total weight percentage of clay in each disk and the volume fraction of micro-scale clay clusters identified in Figure 5, it is expected that a 


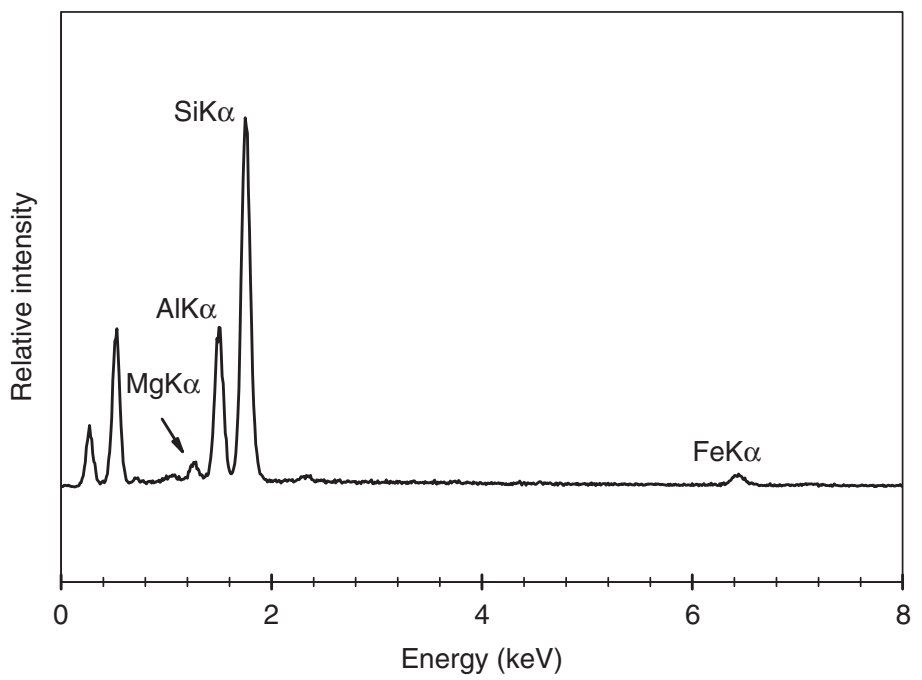

Figure 9. EDS spectrum of Cloisite ${ }^{\circledR} 25 A$ that is used to determine the elements to be targeted by WDS. The spectrum is also given in Ref. [40].

considerable amount of clay remain unidentified in each disk. These unidentified clay clusters could be in the form of smaller intercalated clusters or exfoliated platelets. The dispersion of these so-called nano-scale clusters is quantified by wavelength dispersive spectrometry by analyzing the elemental composition of nanoclay clusters at various radial locations. The particular EMPA analyzer enables the user to select the spot to be analyzed visually by the integrated SEM and light microscope. Therefore, the spots to be analyzed are chosen to exclude micro-scale clusters in order to determine the content of only nano-scale clusters.

Traditionally, the elements that are to be targeted by wavelength dispersive spectrometry were determined by a priori analysis with energy dispersive spectrometry (EDS). For this reason a small amount of compacted of Cloisite ${ }^{\circledR} 25 \mathrm{~A}$ is placed into EMPA and its EDS spectrum is determined. This spectrum, which is also published in Ref. [40], is given in Figure 9. As indicated by the intensity peaks in Figure 9, the major constituent elements are determined as silicon, magnesium, aluminum, and iron. The carbon peak on the low energy side of the spectra is not significant since it originates from the carbon sputtering carried out as a part of sample preparation for EMPA.

In order to assess the resolution of the compositional analysis by wavelength dispersive spectrometry, $3 \sigma$-minimum detection limits are calculated for individual elements that were targeted. For magnesium, aluminum, silicon and iron, the $3 \sigma$-minimum detection limits are determined as $0.02,0.02,0.03$, and $0.04 \mathrm{wt} \%$ respectively. Therefore it can be concluded that the peak to background intensity and counting times used in this study are adequate.

The major elements determined by EDS are targeted by wavelength dispersive spectrometry (WDS). At least 120 points at a distance of $500 \mu \mathrm{m}$ from each other are targeted along the center-line of the dispersion characterization samples. The distribution of nano-scale nanoclay clusters are depicted in Figure 10. Although the nanoclay content is constant in the radial direction for all three disks, the average nano-scale clay contents are significantly different. The average nano-scale cluster contents are determined as 0.83 , 

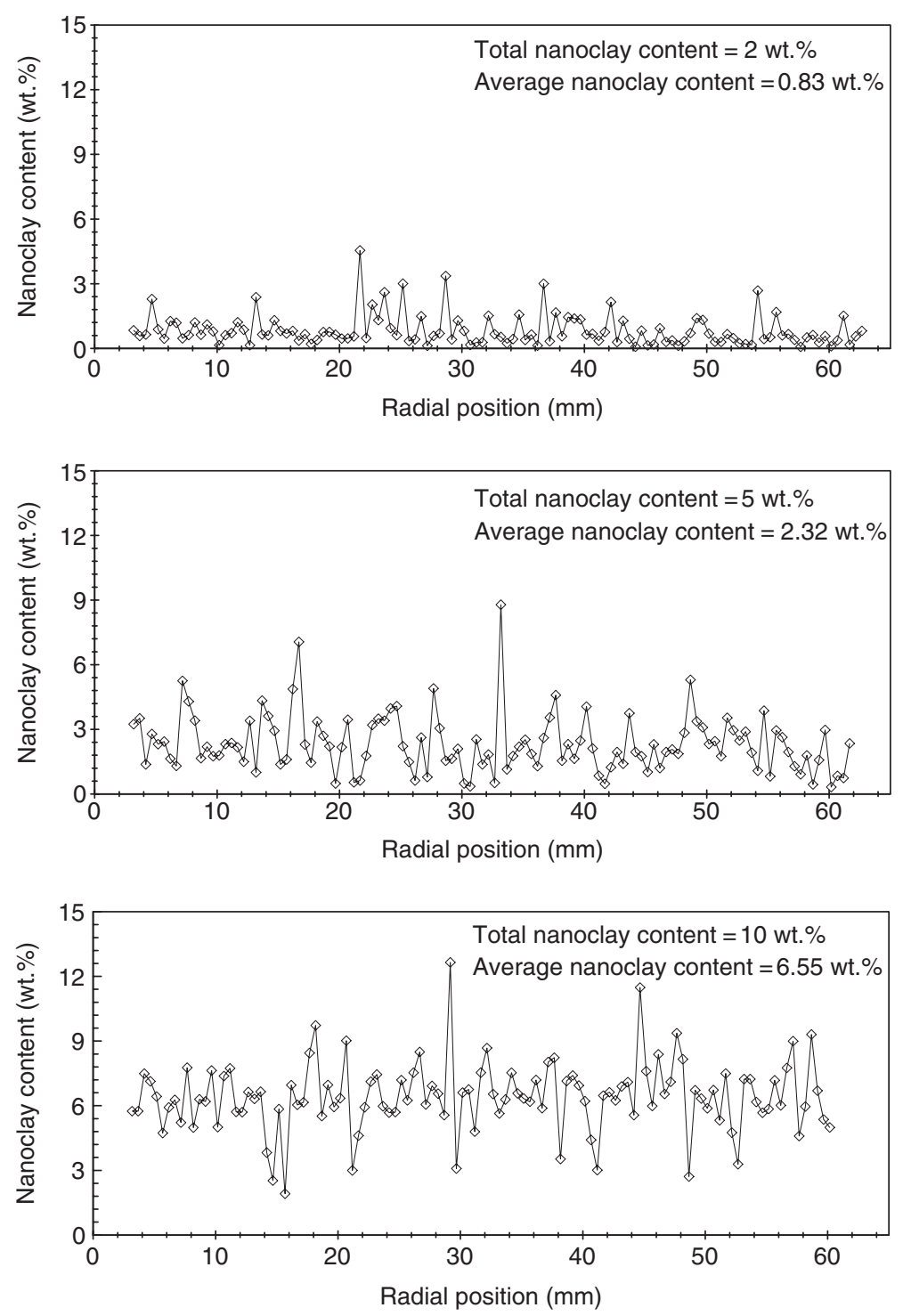

Figure 10. Radial distribution of nano-scale cluster content along the radius of the nanocomposite disks as obtained by WDS.

2.32, and $6.55 \mathrm{wt} \%$ for disks with 2,5 , and $10 \mathrm{wt} \%$ nanoclay. These results indicate that approximately half of the total nanoclay that is included in the epoxy matrix dispersed to particle sizes smaller than $1.5 \mu \mathrm{m}$. Note that, although the micro-scale clay content is decreasing in the radial direction for composites with 5 and $10 \mathrm{wt} \%$ nanoclay, nano-scale clay content remains constant. This indicates that the clusters with planar dimensions smaller than $1.5 \mu \mathrm{m}$ can pass through the openings between glass fibers, without being subjected to filtration. Thus, one can conclude that a homogenous distribution of clay in a resin transfer molded composite can only be achieved if the clay clusters are broken and dispersed down to sub-micron scale. 


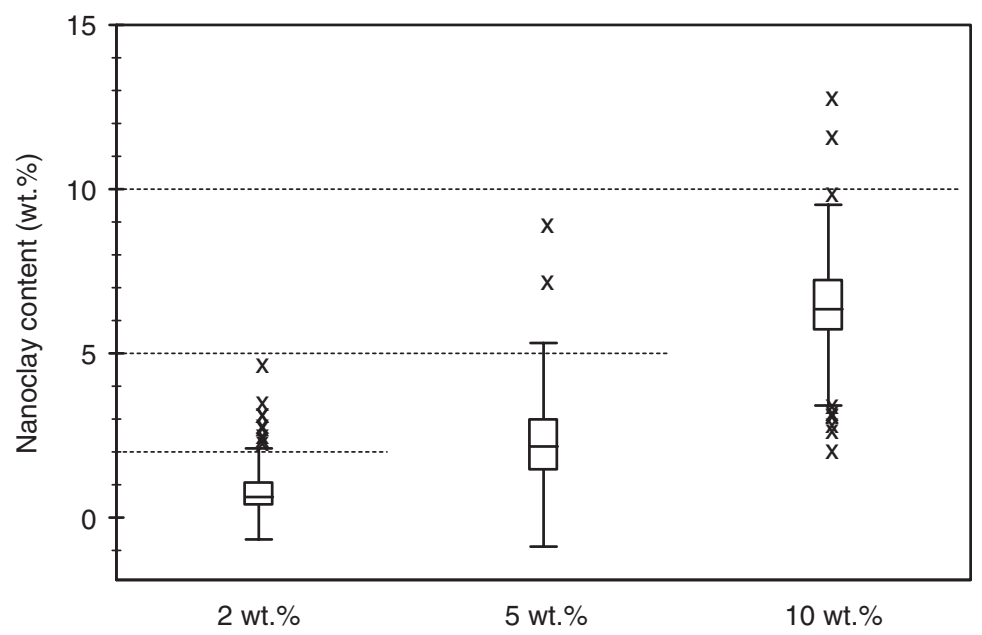

Figure 11. Box and whiskers plot indicating the median nano-scale cluster content and outlier data points for the disks with different nanoclay contents.

It can be observed from Figure 10 that the nano-scale clay content results obtained from WDS have large data scatters, with a number of data points notably above the average clay contents. In order to assess the validity of the nano-scale clay contents presented in Figure 10, an outlier analysis is performed. One method of performing the outlier analysis is by forming a box and whiskers plot as described in Ref. [41]. To accomplish this, the median, quartiles, and fences are determined for the WDS data and presented in Figure 11 for each disk. The upper and lower fences for the WDS data (Figure 10) are determined as 2.1 and $-0.7 \%, 5.3$ and $-0.9 \%, 9.5$ and $3.4 \%$, for composite disks with 2,5 , and $10 \mathrm{wt} \%$ clay loading, respectively. Accordingly, the outliers, which are outside the fences, are indicated in Figure 11 by crosses. One possible reason for the outliers may be the presence of micro-scale clusters in the analytical volume. Although special attention is paid not to include micro-scale nanoclay clusters in the analytical volume, at a number of locations, these clusters may have been inadvertently included in the analyses resulting in overestimated nano-scale cluster contents. The average nano-scale cluster contents are recalculated by excluding the outliers as $0.66,2.23$, and $6.53 \mathrm{wt} \%$ for composite disks with 2,5 , and $10 \mathrm{wt} \%$ clay loadings, respectively. These values are very close to the average values presented in Figure 10, indicating that the effect of inadvertent inclusion of micro-scale clusters is negligible.

\section{Dynamic Mechanical Analysis}

Dynamic mechanical analysis is especially significant in nanoclay/polymer composites as its results may indicate intercalation of nanoclay by the polymer. Particularly, when the nanoclay is intercalated by the polymer, the platelets constrain the glass transition relaxation at a molecular level, and result in an elevated glass transition temperature. In order to investigate whether the nano-scale nanoclay clusters are in fact intercalated, glass transition temperature of four samples from composite disks with $0,2,5$, and $10 \mathrm{wt} \%$ nanoclay are determined. 


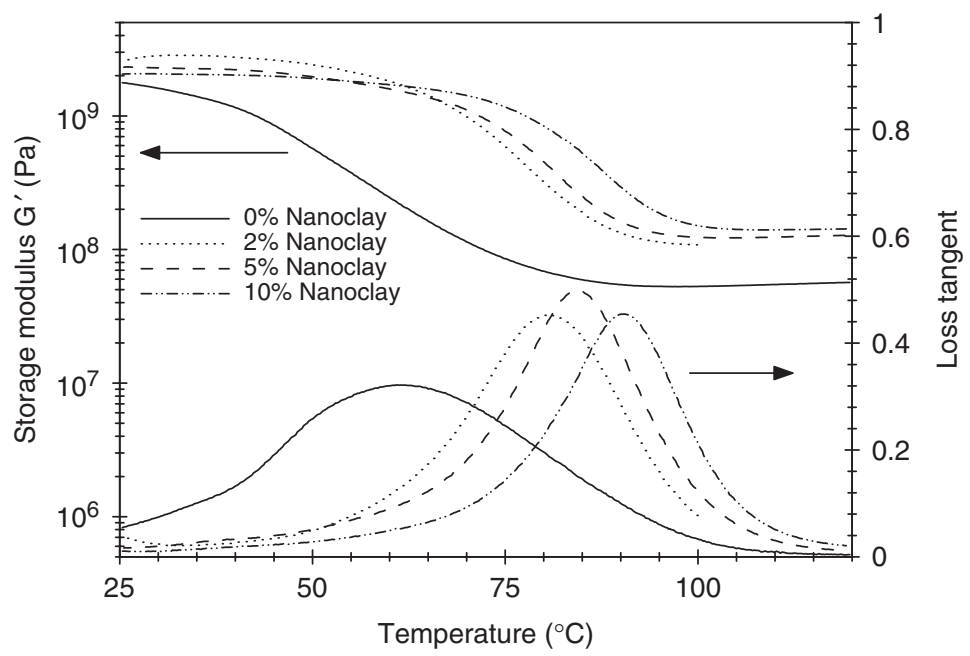

Figure 12. Storage modulus and loss tangent as a function of temperature for the disks with different nanoclay contents.

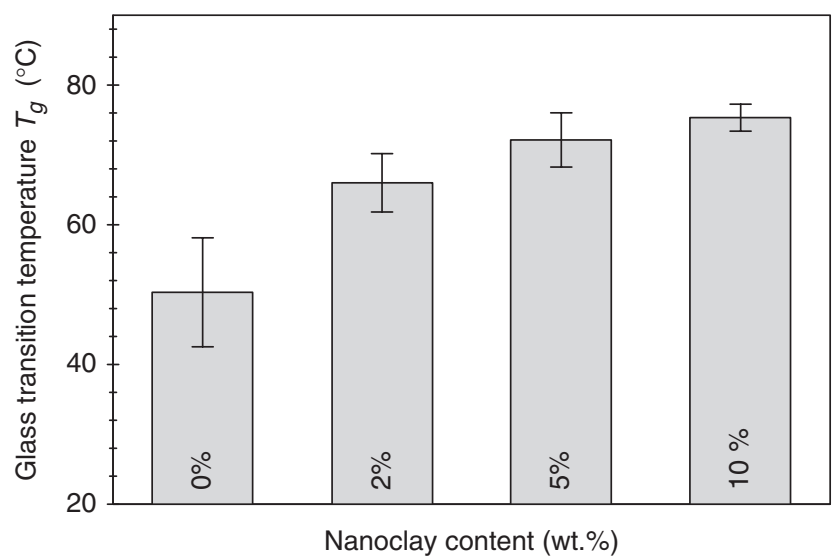

Figure 13. Glass transition temperature increases with nanoclay addition.

Glass transition temperature is most often determined in three ways: (i) the onset of storage modulus reduction, (ii) the peak of loss modulus, and (iii) the peak of loss tangent [42]. In this study, glass transition temperature based on the onset of storage modulus reduction is reported. This value is particularly significant as it indicates the temperature at which the stiffness of the parts starts deteriorating. The storage modulus and loss tangent curves for the aforementioned composites are depicted in Figure 12 as a function of temperature. It should be noted that post glass transition storage moduli of the composite disks containing nanoclay are significantly superior to the composite disk without nanoclay. This indicates that the high temperature durability of the composite disks is notably improved by the addition of nanoclay.

The glass transition temperature values obtained by the average of four samples for each of the nanocomposite disks are presented in Figure 13 together with 95\% confidence intervals. The glass transition temperature for glass/epoxy disks with $0,2,5$, and $10 \mathrm{wt} \%$ 
nanoclay is determined as $50.3,66.0,72.2$, and $75.3^{\circ} \mathrm{C}$, respectively. The increasing trend in glass transition temperature with the addition of nanoclay indicates that nanoclay is at least partially intercalated by the epoxy resin [43].

\section{CONCLUSIONS}

Dispersion of nanoclay in resin transfer molded nanoclay/glass/epoxy disks is characterized at two length scales. To perform dispersion analysis, four center-gated composite disks containing $14 \%$ glass fiber preform are molded with $0,2,5$, and $10 \mathrm{wt} \%$ Cloisite $^{\circledR} 25 \mathrm{~A}$. An electron microprobe analyzer is utilized to characterize the dispersion of nanoclay in the radial direction of these nanocomposite disks. Nanoclay clusters larger than $1.5 \mu \mathrm{m}$ are characterized by performing digital image analysis on the scanning electron micrographs taken at $50 \times$, whereas smaller nanoclay clusters which are not visible on the micrographs are quantified by wavelength dispersive spectrometry.

Digital image analysis indicates that micro-scale nanoclay cluster distribution is not radially uniform due to filtration of clay clusters by the fiber preform and breakdown of clusters during mold filling. Filtration of clay clusters result in significant reductions in cluster content in the radial direction. For instance, 39 and $50 \%$ less micro-scale clusters are found at the outer edges of the disks with 5 and $10 \mathrm{wt} \%$ nanoclay, respectively. The breakdown of clusters, on the other hand, is observed to yield a non-homogenous cluster size distribution, such that, the outer edges of the disks contain finer particles. For instance, the contribution of small micro-scale clusters is $10-20 \%$ higher at the outer edges for all the molded nanocomposites.

Variation of nanoclay clusters smaller than $1.5 \mu \mathrm{m}$ did not display a definite trend in the radial direction. It can be concluded from the wavelength dispersive spectrometry data that approximately $50 \%$ of the total clay content in each disk is dispersed to particle sizes smaller than $1.5 \mu \mathrm{m}$ which are likely to be intercalated by the epoxy resin. Dynamic mechanical analysis indicate that the glass transition temperature is increasing with the addition of nanoclay indicating that some of the nanoclay platelets are intercalated by the epoxy resin and are taking part in the molecular relaxation mechanism of the epoxy matrix.

\section{REFERENCES}

1. Nakamura, Y., Yamaguchi, M., Okubo, M. and Matsumoto, T. (1992). Effect of Particle-Size on Mechanical-Properties of Epoxy-Resin Filled with Angular-Shaped Silica, Journal of Applied Polymer Science, 44(1): 151-158.

2. LeBaron, P.C., Wang, Z. and Pinnavaia, T.J. (1999). Polymer-Layered Silicate Nanocomposites: An Overview, Applied Clay Science, 15(1-2): 11-29.

3. Ahmadi, S.J., Huang, Y.D. and Li, W. (2004). Synthetic Routes, Properties and Future Applications of Polymer-Layered Silicate Nanocomposites, Journal of Materials Science, 39(6): 1919-1925.

4. Theng, B.K.G. (1979). Formation and Properties of Clay-Polymer Complexes, Elsevier Scientific Publishing Company, New York.

5. Usuki, A., Kawasumi, M., Kojima, Y., Okada, A., Kurauchi, T. and Kamigaito, O. (1993). Swelling Behavior of Montmorillonite Cation Exchanged for Omega-Amino Acids by EpsilonCaprolactam, Journal of Materials Research, 8(5): 1174-1178. 
6. Usuki, A., Kojima, Y., Kawasumi, M., Okada, A., Fukushima, Y., Kurauchi, T. and Kamigaito, O. (1993). Synthesis of Nylon 6-Clay Hybrid, Journal of Materials Research, 8(5): 1179-1184.

7. Kojima, Y., Usuki, A., Kawasumi, M., Okada, A., Fukushima, Y., Kurauchi, T. and Kamigaito, O. (1993). Mechanical-Properties of Nylon 6-Clay Hybrid, Journal of Materials Research, 8(5): 1185-1189.

8. Fukushima, Y. and Inagaki, S. (1987). Synthesis of An Intercalated Compound of Montmorillonite and 6-Polyamide, Journal of Inclusion Phenomena, 5(4): 473-482.

9. Cho, J.W. and Paul, D.R. (2001). Nylon 6 Nanocomposites by Melt Compounding, Polymer, 42(3):1083-1094.

10. Maiti, P., Nam, P.H., Okamoto, M., Hasegawa, N. and Usuki, A. (2002). Influence of Crystallization on Intercalation, Morphology, and Mechanical Properties of Polypropylene/ Clay Nanocomposites, Macromolecules, 35(6): 2042-2049.

11. Chen, L., Wong, S.C. and Pisharath, S. (2003). Fracture Properties of Nanoclay-Filled Polypropylene, Journal of Applied Polymer Science, 88(14): 3298-3305.

12. Liu, T.X., Lim, K.P., Tjiu, W.C., Pramoda, K.P. and Chen, Z.K. (2003). Preparation and Characterization of Nylon 11/Organoclay Nanocomposites, Polymer, 44(12): 3529-3535.

13. Wang, D.Y., Zhu, J., Yao, Q. and Wilkie, C.A. (2002). A Comparison of Various Methods for The Preparation of Polystyrene And Poly(Methyl Methacrylate) Clay Nanocomposites, Chemistry of Materials, 14(9): 3837-3843.

14. Shah, R.K. and Paul, D.R. (2004). Nylon 6 Nanocomposites Prepared By a Melt Mixing Masterbatch Process, Polymer, 45(9): 2991-3000.

15. Shen, L., Phang, I.Y., Chen, L., Liu, T.X. and Zeng, K.Y. (2004). Nanoindentation and Morphological Studies on Nylon 66 Nanocomposites. I. Effect of Clay Loading, Polymer, 45(10): 3341-3349.

16. Xu, L.Q. and Lee, L.J. (2004). Effect of Nanoclay on Shrinkage Control of Low Profile Unsaturated Polyester (UP) Resin Cured at Room Temperature, Polymer, 45(21): 7325-7334.

17. Lan, T. and Pinnavaia, T.J. (1994). Clay-Reinforced Epoxy Nanocomposites, Chemistry of Materials, 6(12): 2216-2219.

18. Abot, J.L., Yasmin, A. and Daniel, I.M. (2003). Mechanical and Thermoviscoelastic Behavior Of Clay/Epoxy Nanocomposites, Materials Research Society Symposium Proceedings, 740: I6.5.1-I6.5.6.

19. Pinnavaia, T.J., Lan, T., Kaviratna, P.D., Wang, Z. and Shi, H.H. (1995). Clay-Reinforced Epoxy Nanocomposites - Synthesis, Properties and Mechanism of Formation, Abstracts of Papers of the American Chemical Society, 210: 61-MSE.

20. Wang, M.S. and Pinnavaia, T.J. (1994). Clay Polymer Nanocomposites Formed from Acidic Derivatives of Montmorillonite and An Epoxy-Resin, Chemistry of Materials, 6(4): 468-474.

21. Timmerman, J.F., Hayes, B.S. and Seferis, J.C. (2002). Nanoclay Reinforcement Effects on the Cryogenic Microcracking of Carbon Fiber/Epoxy Composites, Composites Science and Technology, 62(9): 1249-1258.

22. Becker, O., Varley, R.J. and Simon, G.P. (2003). Use of Layered Silicates to Supplementarily Toughen High Performance Epoxy-Carbon Fiber Composites, Journal of Materials Science Letters, 22(20): 1411-1414.

23. Miyagawa, H., Rich, M.J. and Drzal, L.T. (2004). Amine-Cured Epoxy/Clay Nanocomposites. I. Processing and Chemical Characterization, Journal of Polymer Science Part B-Polymer Physics, 42(23): 4384-4390.

24. Kashiwagi, T., Harris, R.H., Zhang, X., Briber, R.M., Cipriano, B.H., Raghavan, S.R., Awad, W.H. and Shields, J.R. (2004). Flame Retardant Mechanism of Polyamide 6-Clay Nanocomposites, Polymer, 45(3): 881-891.

25. Giannelis, E.P. (1998). Polymer-Layered Silicate Nanocomposites: Synthesis, Properties and Applications, Applied Organometallic Chemistry, 12(10-11): 675-680.

26. Haque, A., Shamsuzzoha, M., Hussain, F. and Dean, D. (2003). S2-Glass/Epoxy Polymer Nanocomposites: Manufacturing, Structures, Thermal and Mechanical Properties, Journal of Composite Materials, 37(20): 1821-1837. 
27. Yasmin, A., Abot, J.L. and Daniel, I.M. (2003). Processing Of Clay/Epoxy Nanocomposites With a Three-Roll Mill Machine, Materials Research Society Symposium Proceedings, 740: 13.7.1-13.7.6.

28. Kornmann, X., Lindberg, H. and Berglund, L.A. (2001). Synthesis of Epoxy-Clay Nanocomposites: Influence of the Nature of the Clay on Structure, Polymer, 42(4): 1303-1310.

29. Cai, J.F.J. and Salovey, R. (1999). Model Filled Rubber IV: Dependence of Stress-Strain Relationship on Filler Particle Morphology, Journal of Materials Science, 34(19): 4719-4726.

30. Singh, R.P., Zhang, M. and Chan, D. (2002). Toughening of a Brittle Thermosetting Polymer: Effects of Reinforcement Particle Size and Volume Fraction, Journal of Materials Science, 37(4): 781-788.

31. Siviour, C.R., Gifford, M.J., Walley, S.M., Proud, W.G. and Field, J.E. (2004). Particle Size Effects on The Mechanical Properties of a Polymer Bonded Explosive, Journal of Materials Science, 39(4): 1255-1258.

32. Wagener, R. and Reisinger, T.J.G. (2003). A Rheological Method to Compare the Degree of Exfoliation of Nanocomposites, Polymer, 44(24): 7513-7518.

33. Bragg, W.H. and Bragg, W.L. (1913). The Reclection of X-Rays By Crystals, Proceedings of the Royal Society of London (A), 88: 428-438.

34. Cloisite ${ }^{\circledR}$ 25A Material Data Sheet, Southern Clay Products Inc., Gonzales, TX.

35. Olivero, K.A., Hamidi, Y.K., Aktas, L. and Altan, M.C. (2004). Effect of Preform Thickness and Volume Fraction on Injection Pressure and Mechanical Properties of Resin Transfer Molded Composites, Journal of Composite Materials, 38(11): 937-957.

36. Barraza, H.J., Hamidi, Y.K., Aktas, L., O'Rear, E.A. and Altan, M.C. (2004). Porosity Reduction in The High-Speed Processing of Glass-Fiber Composites By Resin Transfer Molding (RTM), Journal of Composite Materials, 38(3): 195-226.

37. Ronnhult, T., Brox, B. and Fritze, G. (1987). The Influence of Surface-Topography on the X-Ray-Intensity in Electron-Microprobe Analysis (Eds/Wds), Scanning, 9(2): 81-87.

38. Hamidi, Y.K., Aktas, L. and Altan, M.C. (2008). Effect of Nanoclay Content on Void Morphology in Resin Transfer Molded Composites, Journal of Thermoplastic Composite Materials, 21(2): 141-163.

39. Aktas, L., Dharmavaram, S., Hamidi, Y.K. and Altan, M.C. (2005). Quantitative Analyses of Nanoclay Dispersion in Molded Epoxy Disks: Effects of Mixing Temperature, In: Nanomaterials: New Research, Nova Science Publishers, Hauppauge, New York, pp. 197-218.

40. Aktas, L., Hamidi, Y.K. and Altan, M.C. (2004). Characterisation of Nanoclay Dispersion in Resin Transfer Moulded Glass/Nanoclay/Epoxy Composites, Plastics, Rubbers and Composites, 33(6): 267-272.

41. Tamhane, A.C. and Dunlop, D.D. (2000). Statistics and Data Analysis, Prentice Hall, Upper Saddle River, New Jersey.

42. ASTM E1640-99, 'Standard Test Method for Assignment of the Glass Transition Temperature by Dynamic Mechanical Analysis'.

43. Tien, Y.I. and Wei, K.H. (2002). The Effect of Nano-Sized Silicate Layers From Montmorillonite on Glass Transition, Dynamic Mechanical, and Thermal Degradation Properties of Segmented Polyurethane, Journal of Applied Polymer Science, 86(7): 1741-1748. 